\title{
Comparison of ETF's performance related to the tracking error
}

\author{
Michaela Dorocáková \\ Department of Banking and International Finance, \\ University of Economics in Bratislava \\ Slovakia \\ michaela.dorocakova@gmail.com
}

\begin{abstract}
With the development of financial markets, there is also immediate expansion of fund industry, which is a representative issue of collective investment. The purpose of index funds is to replicate returns and risk of underling index to the largest possible extent, with tracking error being one of the most monitored performance indicator of these passively managed funds. The aim of this paper is to describe several perspectives concerning indexing, index funds and exchange-traded funds, to explain the issue of tracking error with its examination and subsequent comparison of such funds provided by leading investment management companies with regard to different methods used for its evaluation. Our research shows that the decisive factor for occurrence of copy deviation is fund size and fund's stock consolidation. In addition, performance differences between exchange-traded fund and its benchmark tend to show the signs of seasonality in the sense of increasing in the last months of a year.
\end{abstract}

Keywords: risk diversification, passive investment strategy, indexing, exchangetraded funds, tracking error.

\section{JEL Classification: G11, G15, G23}

\section{INTRODUCTION}

Nowadays fund industry is experiencing high rates of development and there is a large variety of mutual or investment trust types available for investors all over the world. The main reason why these financial instruments are in the center of interest of not only institutional investors but also general public is fair risk diversification for particular assets and portfolio of assets as a whole. Elimination of risk is possible though in the case of non-systematic risk specific for each security. Financial assets are exposed to market risks, including threats of change in interest rates, lower liquidity, political instability and other systematic risks which are practically independent on whether there are more or less assets in a portfolio. Risk diversification is the core pillar of the portfolio theory, founded by Henry Markowitz and later 
developed into the capital asset pricing model in its various forms or multifactor models by Fama and French, including, inter alia, such important element as the main principle of collective investment.

Funds, whether mutual, investment or pension, are collective investment vehicles. Investors are motivated to invest into these instruments not only due to elimination of risks of a portfolio through allocating free funds into several assets. Funds enable small investors be more involved in large-scale investments, which they probably will not be able to afford as individuals. They also offer some other advantages, such as the possibility to transform the share in a fund into its more liquid form in relatively short time, delegation of responsibility for monitoring the actual situation and competent asset management etc. Usually, they could bring higher returns as compared to conservative ways of appreciating savings, however, with a higher degree of risk incurred and accompanied by significant volatility and instability at financial markets. In addition, index funds, which are one of the youngest among all types of funds, combine the benefits of passive investment, especially low transaction cost and management fees derived from passive strategy and the character of portfolio managing. Indexing is based on picking up almost all titles in the same proportion as they are represented in the index and to maintain it in order to track the index and its returns. The character of indices shows the possibility for low cost exposure to the whole selected market, a particular field of the economy within a country or companies from the area which meet the investor's preferences.

The purpose of this article is to describe the issue of tracking error as applied to ETF funds and to demonstrate it on the examples of selected funds by comparing such investment instruments provided by the world famous management corporations. We present an overview of theoretical background and empirical researches in the area of passive investments and tracking error of the index funds. We then make calculations of this variance in copying a benchmark for the selected exchange-traded funds with the aim to identify the decisive factors behind the tracking error occurence. For this purpose, data from BlackRock, Vanguard and Yahoo Finance for the period from September 2010 to March 2016 were gathered.

In the first section, this paper presents multiple views and opinions on various aspects of indexing, index funds, ETF and tracking error of these funds. In the second part we outline the methodology of our research by defining three methods of copy error calculation. The third section presents the results and finally we summarize in the conclusions.

\section{LITERATURE REVIEW}

Although fund industry has got a longer history, index and exchange-traded funds are relatively its young component that roots go back to the late last century. Because of that there appear theoretical publications and empirical studies only in the last decades, which usually deal with passive indexing, comparison of passively managed funds with those, which use active managing strategy or empirical examination of deviation between performance of fund and benchmark or its theoretical background.

Investing is all about common sense, which tells us, and history confirms it, that the simplest and most efficient investment is to buy and hold all of the nation's publicly held businesses at very low cost. Index fund is the only investment that brings you fair share of stock market returns. Such a view presents Bogle (2007) in his book The Little Book of Common Sense Investing.

Professor Malkiel (2011) caused breakthrough in investment opportunities in early 1970s with his world-famous work entitled A random walk down Wall Street: the time-tested strategy for successful investing, when he, as first, admitted to invest in indexes. Passive management funds achieve profitability comparable to the market average. By contrast, funds with an active strategy despite the continual searching for tools, that would outperform the market, achieve lower appreciation. Malkiel justifies it with 
existence of an efficient market in which all information is immediately reflected in the price of securities. The market price is therefore, according to the theory of efficient markets, best estimate of the true values of financial assets. But many economists mistakenly consider efficient markets for high-yield markets, when they equated effectiveness with the economy.

\subsection{Comparison of actively and passively managed funds}

Burgess and O’Dell (1978) from Washington University have analyzed the index efficiency with implication on index funds based on the two different approaches, the mean-variance and the stochastic dominance rules during the period between February 1973 and September 1975. Their purpose was to examine seven popular indexes, forty randomly selected common stock and four mean-variance efficient portfolios that have been compounded according to Markowitz portfolio variance minimizing. They came to the result, that index or pension fund with the underlying index S\&P 500 or DJIA would beat both mutual funds, individual stocks and mean-variance efficient portfolios, too. Better performance of index mutual funds tracking S\&P 500 compared to the active funds after expenses over sample period has been confirmed also in the study by Frino and Galagher (2001), where they have outlined the problems faced by such passive funds and explored the variation and the extend of tracking error in abovementioned funds.

D. Swensen, portfolio manager of Yale University, said: "The chances of beating the market in actively managed funds is less than 1 in 100." Also Professor Chovancová (2005) mentioned higher return compared to actively managed funds as an advantage of index fund in her article Indexove fondy na kapitálových trhoch. Even if at some stage managers of actively managed funds achieved higher profitability compared to market average, it is unlikely to find such a return can be repeated again. There is another risk connected with them, namely that such manager may correct the investing strategy, which will not meet investors' needs and depends solely on the subjective decision of a particular manager. On the other hand there is higher transparency at the index fund, so it is determined at the beginning, which index it tracks and this setting will not change in the future. Another risk related to the manager is his possible inexperience and incompetence, which fund may be issued.

A wide range of index funds not only outperform actively managed portfolios, but this way investors can avoid the higher fee and trading costs, that make the yields lower. Therefore, there is no point to effort on outperforming the market average, which is expressed in the idea, that if you cannot beat them, join them. There has been executing variety of empirical test or analysis, which prove that passively managed funds represented by index funds, usually outperform the funds with active stock-picking strategy in the long-term horizon. Fama in collaboration with French (2010) made a study titled Luck Versus Skill in the Cross Section of Mutual Fund Returns, which compared the performance of 3156 actively managed funds over the period $1984-2006$. They concluded that the average yield of selected funds was by $0.81 \%$ p.a. lower than market returns. In addition to this we understand under the passive investment also the strategy buy-and-hold, when an investor buys bonds to hold them in the portfolio until their maturity.

No one can truly predict market activity to pick right stocks. Everyone, who claims to pick stocks at the right time, is usually riding on luck and truly great investing depends on analyzing historical data over eighty years to provide a more reliable estimate of risks and returns. This fact as well as the aforementioned so-called "time picking" as two of the twelve-step program is described by Hebner and Markowitz (2012) in their handbook called Index Funds: The 12-Step Recovery Program for Active Investors. He characterizes index funds as the safest way to achieve long-term returns. 
How to make the optimal portfolio selection in a period of significant volatility was being examined by Petronio et al. (2014). Evaluation of the performance of exchange-traded funds as a flexible form of passive investment has shown that the strategy based on the Sharpe ratio yields best results on average. The authors have been testing three methods of portfolio selection in total, thus Sharpe strategy, Rachev ratio and one that they themselves designed called PCEV. On the US market Sharpe optimization is even more successful in the worst time of crisis, unlike on the European market, where Sharpe method generates growing returns continuously during the observation timeframe of six years around the global financial crisis. Hassine and Roncalli (2013) also suggest own new method for measuring the performance of exchange-traded funds, which is based on the value-at-risk. It is considered to be very simple for using it in portfolio selection process, as it handles three parameters, namely the performance differences between such index fund and their benchmark, the volatility of tracking error and the liquidity spread, while this last parameter is presented as crucial for evaluating efficiency of exchange-traded funds especially in the case of institutional investors.

Two long term investment strategies, namely the long term regular investing into the conservative money market instruments and indexing in three countries during the period of last almost thirty years, have been compared by Chovancová and Árendás (2015) in order to apply it as a base of capitalization pillars of pension systems. They have shown except that in the long term the impacts of market turbulences are eliminated by cost averaging effect of regular investments, between 1985 and 2014 indexing strategy has experienced better outcomes than investments into the deposit accounts, treasury bills or other instruments of short maturities.

\subsection{Exchange-traded funds, index replicating and tracking error}

As mentioned above, results of many studies and lots of another analysis prove that passive investment strategies gain higher returns compared to the active one in the long-term horizon, while investors are recommended to invest for minimum $5-7$ years, respectively 10 years. This strategy is based, except of Markowitz theory of optimal portfolio, on the assumptions of long-term growth of economy and stock markets, as well, despite of fluctuations in short-term period. Typical form of passive strategy is "buy-and-hold" consisting of purchasing of financial instruments and holding them for a long time, respectively until their maturity in the case of interest bonds. Passive character of funds based on the strategy of indexing is expressed in picking up all of the titles included in benchmark market index.

Exchange-traded funds, whose securities are traded at the secondary market, pose as one type of index funds, however, in the case that they are index-linked. Compared to the classic index mutual funds, that accept cash from investors in order to purchase stocks for them, they work on the basis of creation/redemption in-kind. Main differences between these two investment opportunities are (Kostovetsky, 2003):

- management fees;

- shareholder transaction fees;

- taxation efficiency;

- type and convenience of trading.

Exchange-traded funds can significantly reduce the expense ratio because they do not have to handle the shareholder accounting, which constitutes its preponderant part. High liquidity lowers the bid-ask spreads allowing the elimination of the shareholder transaction cost arising from fees to market makers and commissions to brokerage houses. Shareholders must incur taxation cost in the case of distribution of capital gains, which are immediately taxed. 
Passive investment strategy in the case of index funds is based on the most exact tracking of selected benchmark. However, index replication is not as passive, as it would seem at the beginning, due to keeping the tracking error at the lowest possible level, since the tracking error is considered for indicator of portfolio performance and of manager's ability to copy the index precisely. From an economic perspective it could be defined as a degree of differentiation of index fund's portfolio performance from the return of underlying index. From a mathematical-statistical standpoint it expresses a standard deviation of difference between returns of index fund and appreciation of asset value involved in relevant index for a given period.

The appearance of this error is actually unavoidable and necessary, because the benchmark is measured as a so-called paper portfolio and it assumes that full copying can be reached instantaneously and without cost (Frino et al., 2004). We identify two components of tracking error. Portfolio managers are able to influence endogenous tracking error contrast to exogenous component, which is devoted from index design and maintenance procedures and is not under control of decision-makers. Tracking error most of all depends on:

- number of index revisions;

- share issuances;

- share repurchases;

- spin-offs;

- strategy of index replicating;

- fund size;

- dividend policy;

- premium and discount to net asset value;

- season in year.

Vardharaj et al. (2004) defines tracking error as a standard deviation of difference between index performance and relevant portfolio performance, while he identifies determinants for equity portfolio, namely portfolio market capitalization, number of stocks in it, its beta style differences compared to underlying index, sector deviation from the benchmark and benchmark volatility. R. Jansen and R. van Dijk (2002) bring new mathematical methods for portfolio optimization in order to minimize tracking error of portfolio with small number of stocks and they results could be used for solving portfolio construction problems as well.

On the other hand, tracking error minimization as a constraint is considering in the empirical study Index Changes and Losses to Index Fund Investors (Chen et al., 2006), because this purpose leads to losses of investors into the index funds. Losses resulting from unrealized returns are caused by arbitration activity, which is allowed thanks to reconstitutions in index composition. The authors have examined the consequences of changes in one large-cap index S\&P 500 and one small-cap index Russell 2000. These changes in indices have to comply with several conditions, from which we would highlight the necessity of transparent changes, which have to be announced in sufficient advance of the validity day. Moreover, the authors suggest possible solutions, which could eliminate arbitrations. One of the theoretical possibilities are silent indices, where changes in contrast to the typical indexes are not disclosed unless they are valid or rarely used indexes whose passive indexing does not exceed $1 \%$ of the market value of all stocks in the index. In the terms of popular indexes, there are in fact unavoidable losses, but they can be minimized by reducing the amount and predictability of index reorganizations and there should be also obscured the process of index changes without their preliminary notification.

Tracking error however from the approach of minimization of tracking error variance is been considering by Roll (1992). During the derivation of suitable compositions of the particular portfolios 
maximizing average performance over a benchmark for a given minimum level of tracking error volatility into so-called TEV frontier, author criticizes this strategy of fund managers. Indeed thus constructed portfolio while respecting the criteria of minimizing tracking error volatility does not correspond to the mean/variance Markowitz efficient portfolio exhibits a beta greater than 1.0 and cannot be superior to benchmark by having higher expected return and lower total volatility.

\section{METHODOLOGY}

Our research focuses on examination of tracking error of selected exchange-traded funds providing by leading investment companies. Our attention is paid to world-famous indexes, that allow gain the exposure up to $3 / 4$ US stock market in the case of S\&P 500 and the exposure to the number of US companies with small capitalization, which represents $8 \%$ of Russell 3000 covering almost whole US investable equity market. We make comparison of two funds, which track same index S\&P 500 and one that is compounded to replicate small-cap index Russell 2000, namely:

- Vanguard S\&P 500 ETF by Vanguard Group;

- iShares Core S\&P 500 ETF by BlackRock;

- iShares Russell 2000 ETF by BlackRock.

Tracking error as an indicator of accuracy of copying of index performance used to be measured per monthly or quarterly returns, however also with the aid of daily or annual return, volatility or correlation. In this article there is the calculation of tracking error carried out on the basis of daily returns and later also quarterly returns, using logarithmic returns of net asset value in the case of funds and logarithmic returns of index value. We have used data from the period from September 2010 to March 2016, because we have been constrained by inception day of Vanguard's fund on the 7th September 2010. Tracking error (TE) is usually considered to be a standard deviation of active return, while active return means the difference between the portfolio return and the benchmark return. We have measured it in three a little bit similar, but different ways:

- Vardharaj et al. (2004) defines it as follows:

$$
T E 1=\sqrt{\frac{1}{T-1} \sum_{t=1}^{T}\left(r_{F, t}-r_{I, t}\right)^{2}}
$$

where $\mathrm{T}$ is number of observations, $\mathrm{r}_{\mathrm{F}, \mathrm{t}}$ represents logarithmic return to NAV (net asset value) of an ETF, $\mathrm{r}_{\mathrm{I}, \mathrm{t}}$ represents logarithmic return of underlying index value;

- Shin and Soydemir (2010) use except of regression analysis these methods:

$$
\begin{aligned}
& T E 2=\frac{1}{T} \sum_{t=1}^{T}\left|r_{F, t}-r_{I, t}\right| \\
& T E 3=\sqrt{\frac{1}{T-1} \sum_{t=1}^{T}\left(R D_{t}-\theta R D\right)^{2}}
\end{aligned}
$$

where $R D_{t}=\left|r_{F, t}-r_{I, t}\right|$, $\theta \mathrm{RD}$ means arithmetic average of RD.

The seasonality in performance differences between exchange-traded fund and the index it tracks is illustrated through the box plot, where, as in other figures, absolute values are used. Absolute values of active returns as well as absolute values of returns of funds enable better illustration and are more appropriate from a methodological point of view, while the significance is preserved.

Within the determining of hypotheses we express certain assumptions about the tracking error of the selected exchange-traded funds related to some characteristics of these funds and other factors affecting it. 
Hypothesis 1: Exchange-traded funds with higher management fees, higher trading and rebalancing costs resulting from benchmark index revisions or reconstitution, and with the higher sector deviations of their portfolios tend to report higher level of tracking error.

Hypothesis 2: Exchange-traded funds realizing stock consolidations after that, in addition, the stock price used to move in different way, funds with higher value of net assets, as well as funds, whose portfolio beta varies from the index in larger extent and with the higher volatility of benchmark, because more volatile underlying index is more difficult to mimic it closely, are more susceptible to higher tracking error. Moreover, we suppose, that deviations in returns are showing signs of seasonality across the months during the year.

\section{EMPIRICAL RESULTS AND DISCUSSION}

Comparing two exchange-traded funds tracking the same index, namely S\&P 500 index, we have found out, that significantly higher tracking error in the observed period has been experienced by Vanguard's fund (inception date: 07/09/2010) compared to iShares fund (inception date: 05/15/2000) (see Table 1). Certainly some part of tracking error is caused by differences in portfolio composition however we believe that just to a small extent. While the first mentioned fund has got in its portfolio more titles from the field of information technology and less share of portfolio is invested into the shares of financial companies contrast to index, the constituents of second fund with a smaller tracking error differ from the benchmark in all categories of shares (as of 02/29/2016).

Table 1

Tracking error calculation and standard deviation of selected exchange-traded funds on the basis of daily returns over the period $8^{\text {th }}$ September $2010-8^{\text {th }}$ March 2016

\begin{tabular}{|l|c|c|}
\hline & iShares Core S\&P 500 ETF & Vanguard S\&P 500 ETF \\
\hline Standard deviation & 0.009749 & 0.009754 \\
\hline TE1: & 0.09609 & 0.55700 \\
\hline TE2: & 0.01126 & 0.36057 \\
\hline TE3: & 0.09542 & 0.52842 \\
\hline
\end{tabular}

Source: Author's results.

In addition, expanse ratio does not correspond to the size of tracking error. The iShares Core S\&P 500 ETF (hereafter "IVV") reports expense ratio at the level of $0.07 \%$, The Vanguard S\&P 500 ETF (hereafter "VOO") only $0.05 \%$ (see Table 2). In the terms of median market capitalization of the fund, we do not consider it as a significant error indicator, because VOO, that has got relatively high tracking error, reports its median market capitalization on the same level as IVV. There has occurred stock consolidation as one of the most important source of tracking error. Vanguard Group has realized 1-for-2 reverse share split as of the close of business day on $28^{\text {th }}$ October 2013, what caused that VOO fund's NAV appreciated during October - December 2013 by $116.74 \%$. We have omitted this information on the graph due to better comparison of these two exchange-traded funds (see Figure 1 and Figure 2), even did not include into our calculation. After this share rollback returns of this fund started to diverge from the index to a greater extent, as we expected. 


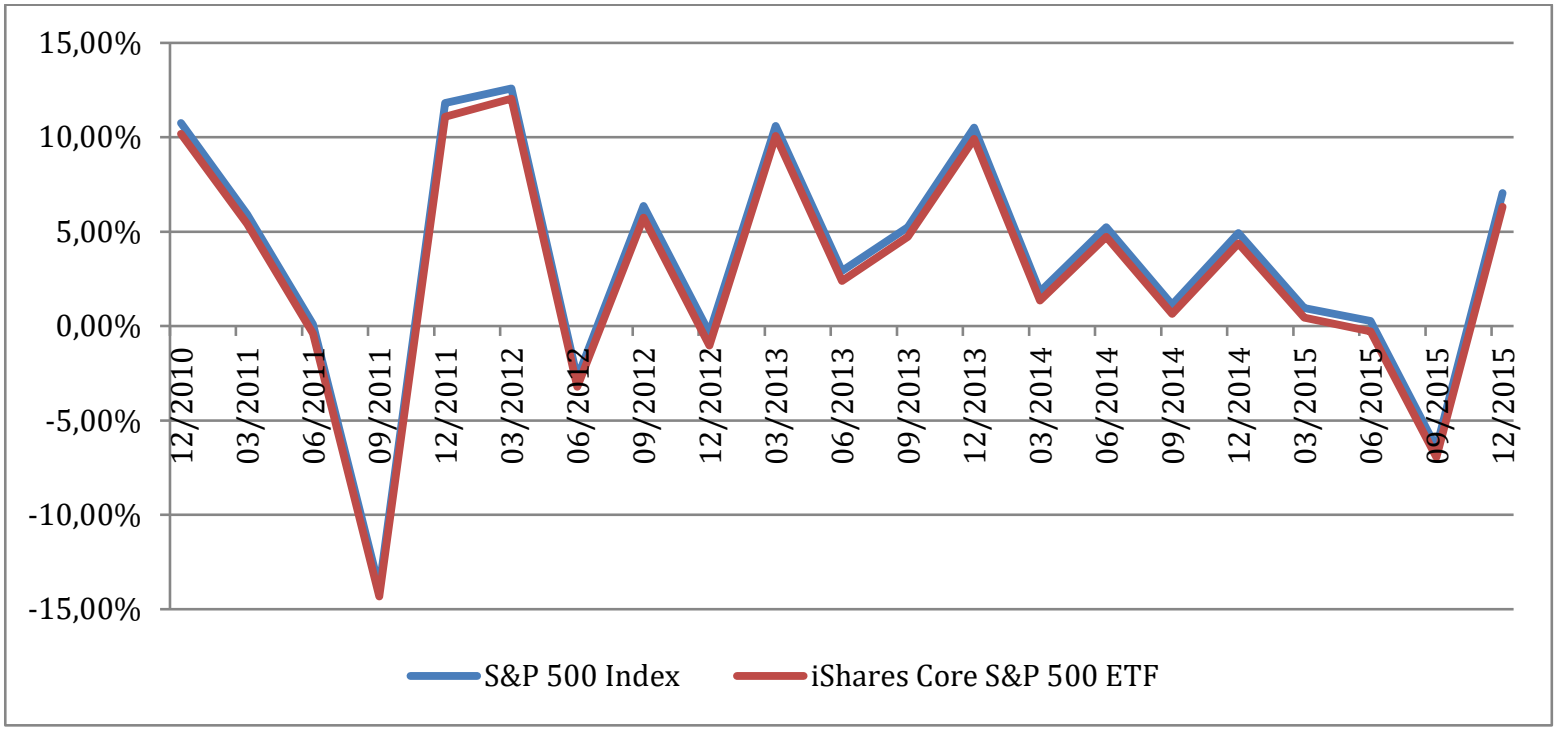

Figure 1. Quarterly returns of iShares Core S\&P 500 ETF and S\&P 500 Index over the period from December 2010 to December 2015

Source: Author's results based on data gathered (BlackRock, Vanguard, Yahoo Finance, 2016).

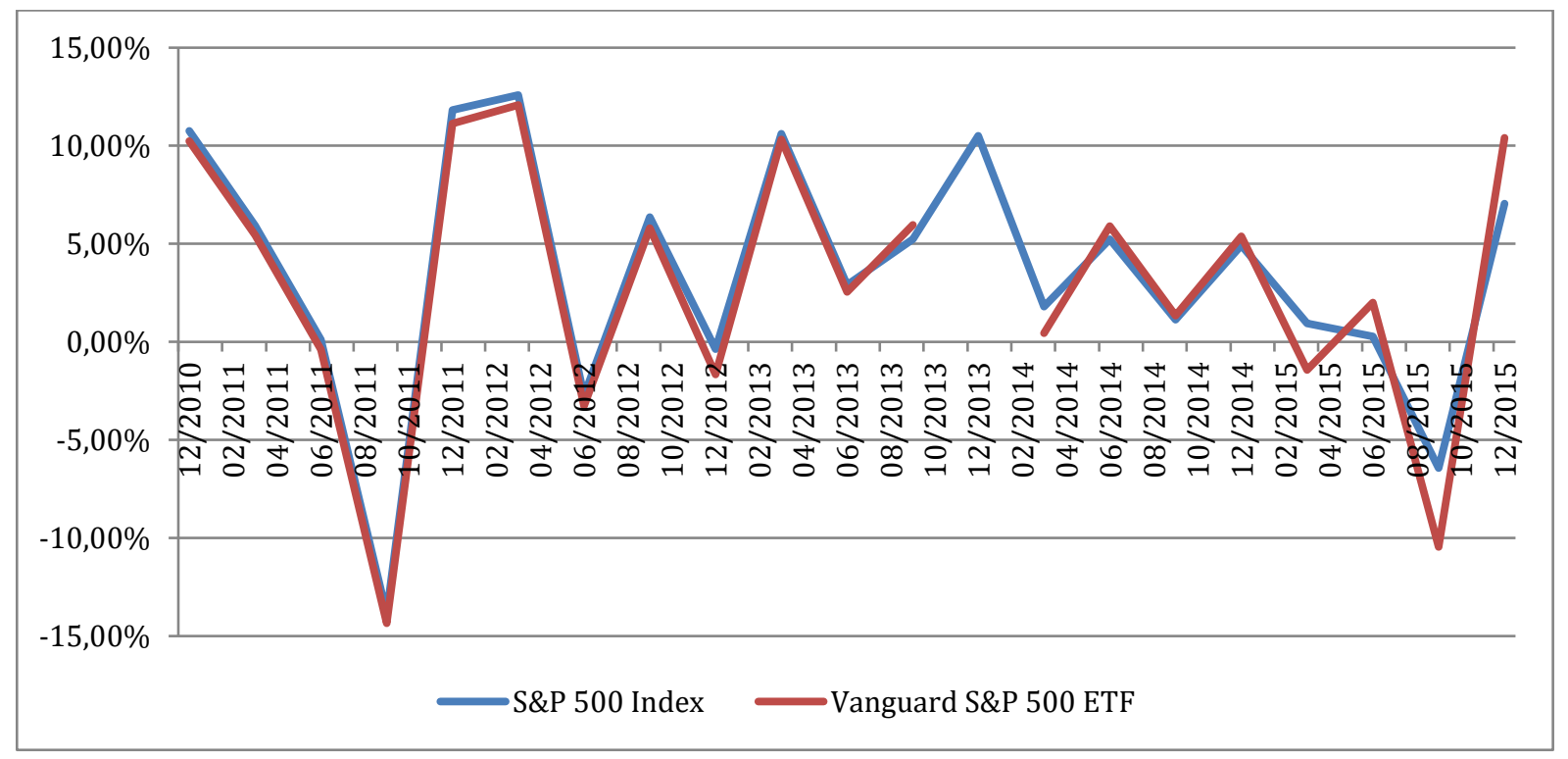

Figure 2. Quarterly returns of Vanguard S\&P 500 ETF and S\&P 500 Index over the period from December 2010 to December 2015

Source: Author's results based on data gathered (BlackRock, Vanguard, Yahoo Finance, 2016).

Using low frequency data, namely quarterly returns, we found out that the values of tracking error of individual funds became closer and tracking error of VOO calculated in all three ways is about twice the value of this error of IVV fund (see Table 2). 
Table 2

Tracking error calculation of selected exchange-traded funds on the basis of quarterly returns over the period 12/2010 - 12/2015 and some fund's characteristics

\begin{tabular}{|c|c|c|c|}
\hline & $\begin{array}{c}\text { iShares Core S\&P } \\
500 \text { ETF }\end{array}$ & $\begin{array}{c}\text { Vanguard S\&P } \\
500 \text { ETF }\end{array}$ & $\begin{array}{c}\text { iShares Russell } \\
2000 \text { ETF } \\
\end{array}$ \\
\hline Standard deviation & 0.0625 & 0.0668 & 0.0898 \\
\hline Minimum & $-14.33 \%$ & $-14.35 \%$ & $-22.36 \%$ \\
\hline Median & $4.37 \%$ & $3.97 \%$ & $3.20 \%$ \\
\hline Maximum & $12.05 \%$ & $12.08 \%$ & $15.69 \%$ \\
\hline TE1: & 0.19290 & 0.32491 & 0.07178 \\
\hline TE2: & 0.11122 & 0.18907 & 0.03770 \\
\hline TE3: & 0.15564 & 0.26423 & 0.06049 \\
\hline Portfolio beta (5y) & 1.00 & 1.00 & 1.21 \\
\hline Expense ratio & $0.07 \%$ & $0.05 \%$ & $0.20 \%$ \\
\hline Net assets (billion, as of $02 / 29 / 2016$ ) & 70.1 & 211.9 & 25.2 \\
\hline
\end{tabular}

Source: Author's results.

Comparing of 5-year-portfolio-beta of these two funds, this part of our hypothesis has been refuted. This assumption is invalid also in the case when we compare the funds that track different benchmark. Portfolio beta of the fund iShares Russel 2000 ETF (hereafter "IWM") has deviated above or below 1.0 as the only, it reports the smallest tracking error. Volatility of benchmark index is not reliable indicator of tracking error level cross-funds, but this volatility pose as a source of this error relatively. Thus, funds replicating index with smaller standard deviation (S\&P 500) have not got smaller error absolutely compared to the funds tracking more volatile index (Russell 2000). However, we identify some positive correlation between active return of selected exchange-traded funds and volatility of their benchmark (see Fig. 3 and Fig. 4).

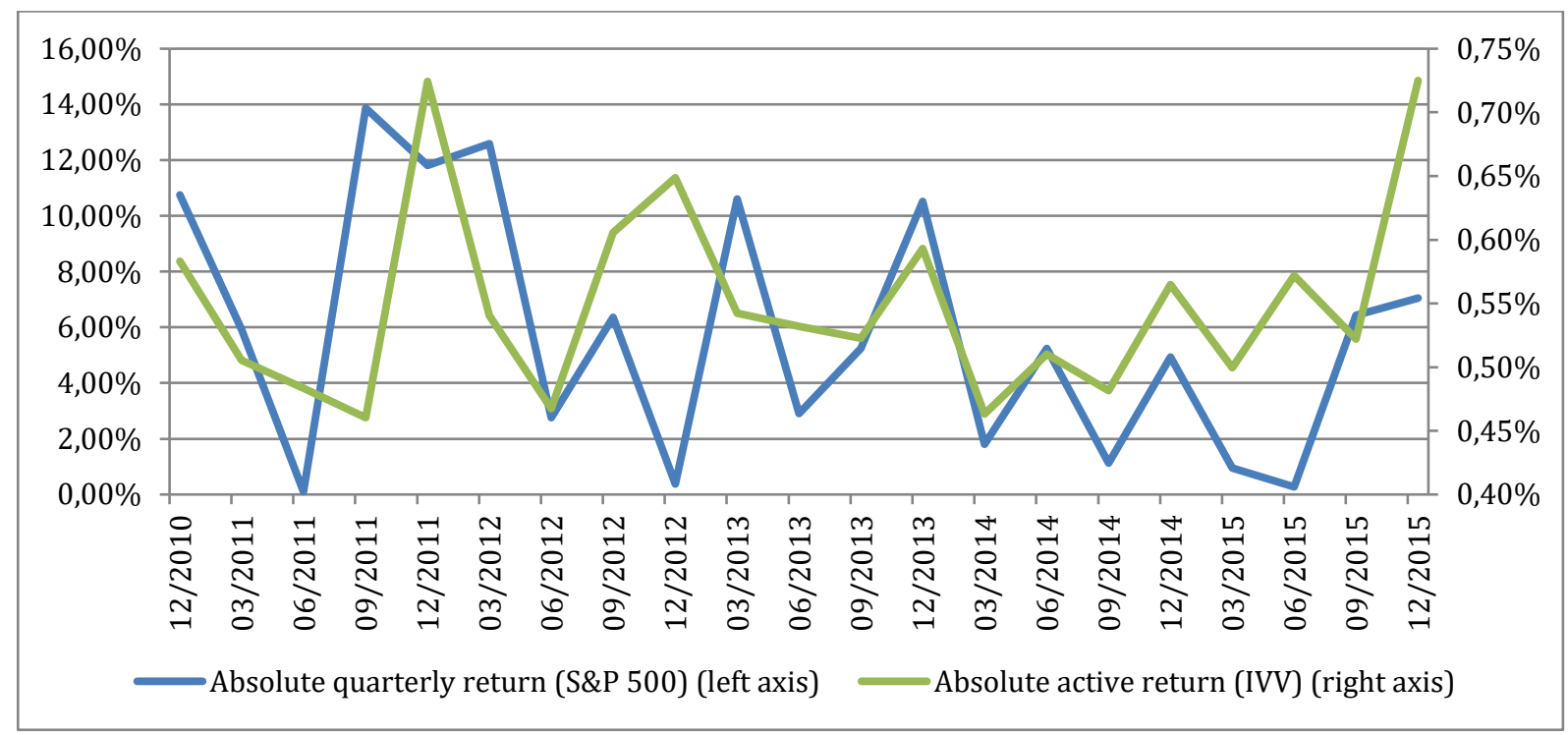

Figure 3. Comparison of quarterly return of benchmark S\&P 500 and active return of iShares Core S\&P 500 ETF in absolute values

Source: Author's results. 


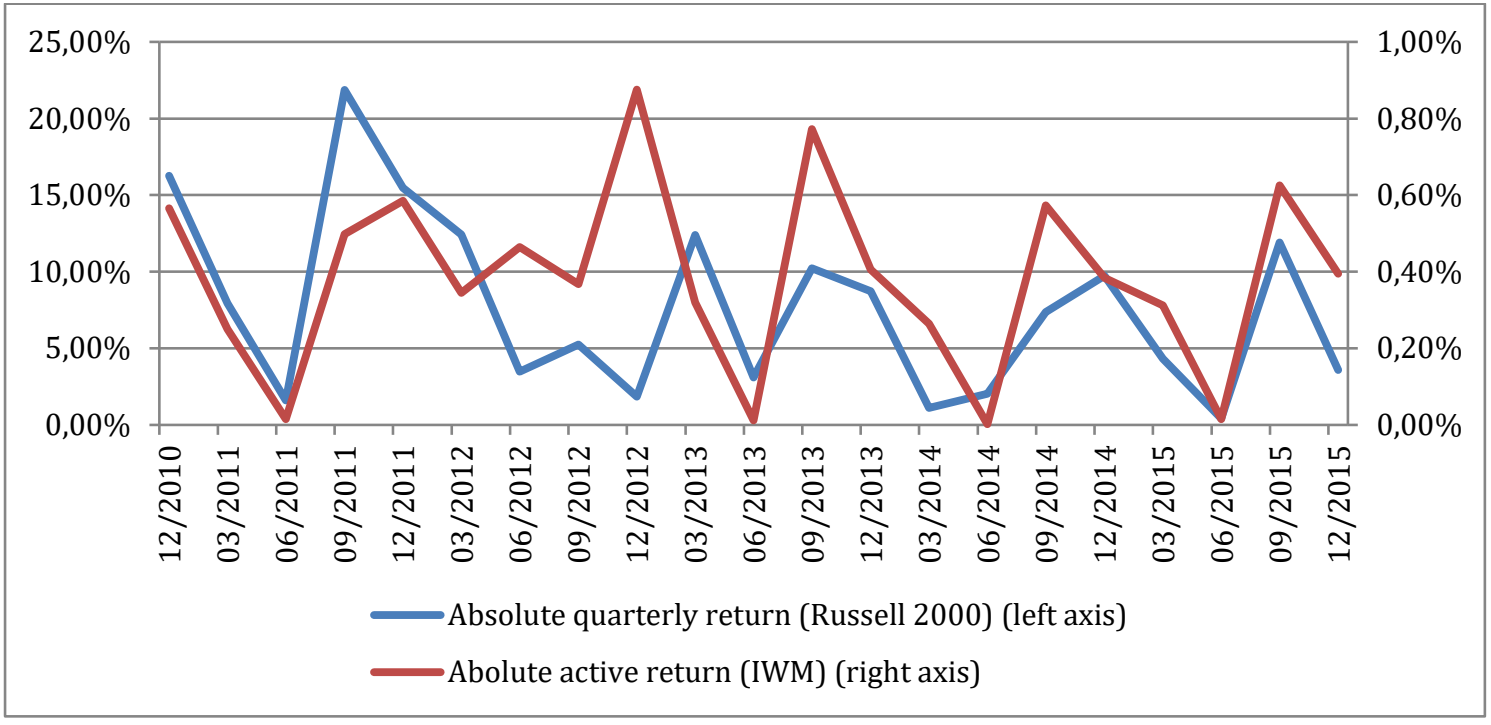

Figure 4. Comparison of quarterly return of benchmark Russell 2000 and active return of iShares Russell 2000 ETF in absolute values

Source: Author's results.

Fund size in the sense of net assets has been shown as a significant factor of tracking error. The higher the value of net asset is, the higher level of tracking error could be recorded (see Table 2). On the contrary, higher number of small-cap Russell 2000's reconstitutions did not lead to higher tracking error in comparison with large-cap S\&P 500, as would be indicated. It is attributed to the fact that changes to this benchmark index occur at fixed intervals in a year with an announcement sufficiently in advance and, moreover, companies that cease to meet the criteria for its inclusion into the index Russell 2000, remain in the index until another reconstitution in following year, which allows to the fund's managers to adapt to this changes and incorporate them.

Finally, the box plots (see Fig. 5 and Fig. 6) clearly show that active return tends to be on the increase in the fourth quarter, respectively during the last months of a particular year, thus our research confirms the seasonality in performance differences between index and relevant exchange-traded funds at least in our observation period.

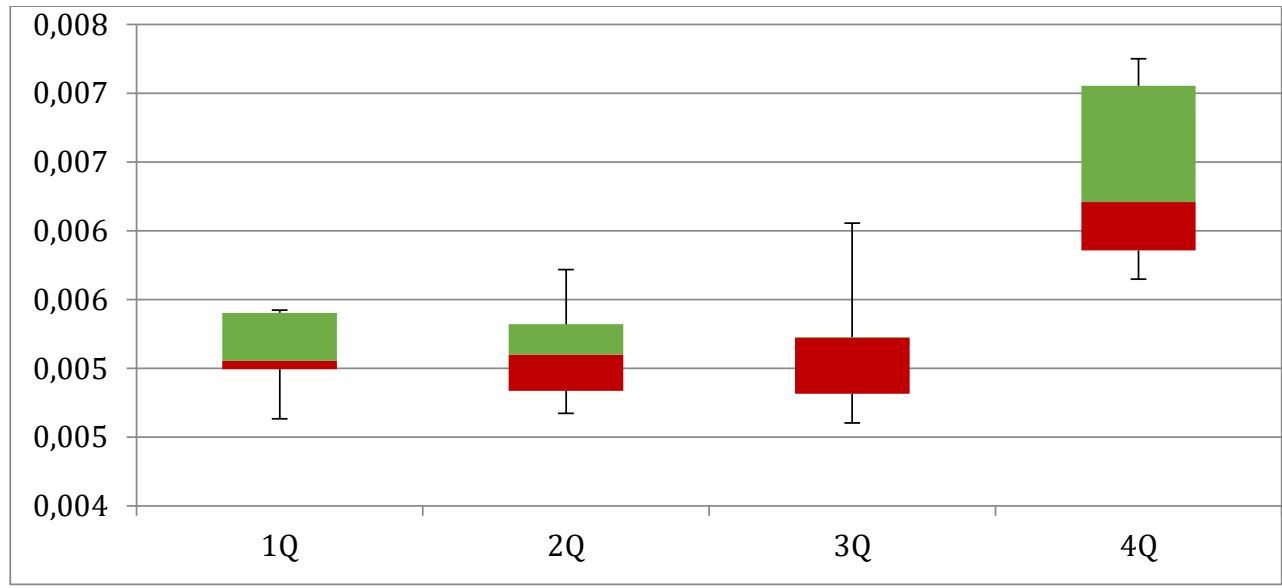

Figure 5. Active return of iShares Core S\&P 500 ETF in absolute value on quarterly basis over the period from December 2010 to December 2015

Source: Author's results. 


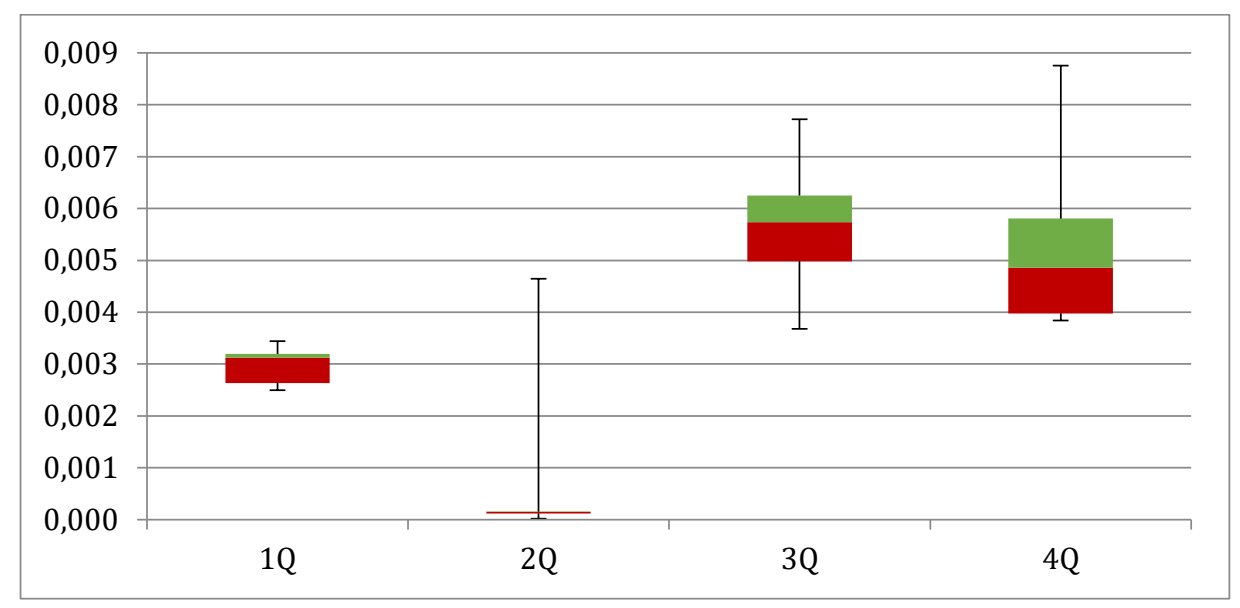

Figure 6. Active return of iShares Russell 2000 ETF in absolute value on quarterly basis over the period from December 2010 to December 2015

Source: Author's results.

\subsection{Potential research biases}

In our research there could be identified some biases:

- selection bias;

- measurement bias.

Selection bias lies in two aspects. Firstly, we have focused our attention on selected factors influencing the tracking error, secondly, we have examined a representative sample of exchange-traded funds, so the final interpretations could vary across the fund industry. During our calculations we had to abstract from the "error values" that have not been able to be calculated and included into the measurement.

\section{CONCLUSION}

The roots of index funds go back to the Markowitz's market portfolio theory. Index funds as one of the forms of passive investment, gain in long-term horizon the comparable returns with actively managed funds, even they outperform them. Exchange-traded funds, working on the basis of creation/redemption in-kind, differ from index mutual funds most of all in management fees, shareholder transaction fees, taxation efficiency, type and convenience of trading. The essence of indexing is on the construction of portfolio from all titles that are included in the benchmark index at equal weights and tracking its performance and risk to the largest possible extent. Tracking error, as a measure of deviation of fund's returns from benchmark's return, is considered to be a criterion for an assessment of fund's fruitfulness in index replication. In our research we found out that expense ratio, portfolio beta, differences in market capitalization between portfolio and underlying index, sector deviations or number of index reconstitution are not sufficient to explain the tracking error differences between analyzed funds, as Frino and Vardaharaj claim. On the other hand, what is consistent with Frino's theory, as an important factor influencing the tracking error we consider the fund's stock consolidation and fund size in the sense of net assets, as well as the tracking error generally tends to grow in the last months of a particular year. The impact of benchmark volatility cannot be observed across the funds, however, fluctuations of underlying index influences the tracking error relatively, thus, these performance differences used to report higher 
values in the times of the highest volatility of benchmark index. Moreover, tracking errors of funds replicating the same index tend to converging by using the lower frequency data.

\section{ACKNOWLEDGEMENT}

This contribution is the result of the project implementation VEGA (1/0009/17) "The making of the Capital union in Europe and its impact on individual member counties".

\section{REFERENCES}

Bogle, J. C. (2007). The little book of common sense investing: the only way to guarantee your fair share of stock market returns. Hoboken, New Jersey: John Wiley \& Sons Inc.

Burgess, R. C., \& O’Dell, B. T. (1978). An Empirical Examination of Index Efficiency: Implications for Index Funds. Journal of Financial and Quantitative Analysis, 13, 93-100. doi: 10.2307/2330524

Fama, E. F., \& French, K. R. (2010). Luck versus Skill in the Cross-Section of Mutual Fund Returns. The Journal of Finance, 65(5), 1915-1947. doi:10.1111/j.1540-6261.2010.01598.x

Frino, A., \& Gallagher, D. R. (2001). Tracking S\&P 500 Index Funds. The Journal of Portfolio Management, 28(1), 44-55. doi:10.3905/jpm.2001.319822

Frino, A., Gallagher, D. R., Neubert, A. S., \& Oetomo, T. N. (2004). Index Design and Implications for Index Tracking. The Journal of Portfolio Management, 30(2), 89-95. doi:10.3905/jpm.2004.319934

Hassine, M., \& Roncalli, T. (2013). Measuring Performance of Exchange-Traded Funds. The Journal of Index Investing, 4(3), 57-85. doi:10.3905/jii.2013.4.3.057

Hebner, M. T., \& Markowitz, H. M. (2012). Index Funds The 12-step Recovery Program for Active Investors. California: IFA Publishing

Chen, H., Noronha, G., \& Singal, V. (2006). Index Changes and Losses to Index Fund Investors. Financial Analysts Journal, 62(4), 31-47. doi:10.2469/ faj.v62.n4.4185

Chovancová, B. (2005), Index Funds in Capital Markets. BIATEC, 13(9), 26-29.

Chovancová, B., \& Árendáš, P. (2015). Long Term Passive Investment Strategies as a Part of Pension Systems. Economics \& Sociology, 8(3), 55-67. doi:10.14254/2071-789x.2015/8-3/4

Jansen, R., \& Dijk, R. V. (2002). Optimal Benchmark Tracking with Small Portfolios. The Journal of Portfolio Management, 28(2), 33-39. doi:10.3905/jpm.2002.319830

Kostovetsky, L. (2003). Index Mutual Funds and Exchange-Traded Funds. The Journal of Portfolio Management, 29(4), 80-92. doi:10.3905/jpm.2003.319897

Malkiel, B. G. (2011). A random walk down Wall Street: the time-tested strategy for successful investing. New York: W. W. Norton.

Petronio, F., Lando, T., Biglova, A., \& Ortobelli, S. (2014). Optimal portfolio performance with exchange traded funds. Ekonomická revue - Central European Review of Economic Issues, 17(1), 5-12. doi:10.7327/cerei.2014.03.01

Roll, R. (1992). A Mean/Variance Analysis of Tracking Error. The Journal of Portfolio Management, 18(4), $13-22$. doi:10.3905/jpm.1992.701922

Shin, S., \& Soydemir, G. (2010). Exchange-traded funds, persistence in tracking errors and information dissemination. Journal of Multinational Financial Management, 20(4-5), 214-234. doi:10.1016/j.mulfin.2010.07.005

Vardharaj, R., Fabozzi, F. J., \& Jones, F. J. (2004). Determinants of Tracking Error for Equity Portfolios. The Journal of Investing, 13(2), 37-47. doi:10.3905/joi.2004.412305

\section{DATABASES}

BlackRock. Retrieved March 18, 2016, from https://www.ishares.com/us

Vanguard. Retrieved March 18, 2016, from http://www.vanguard.com/

Yahoo Finance. Retrieved March 17, 2016, from http://www.finance.yahoo.com/ 